\title{
ВЛИЯНИЕ РН СРЕДЫ ГИДРАТИРУЕМОГО РАСТВОРА НА МОРФОЛОГИЧЕСКИЕ ХАРАКТЕРИСТИКИ ЛЕЦИТИНОВЫХ ЛИПОСОМ
}

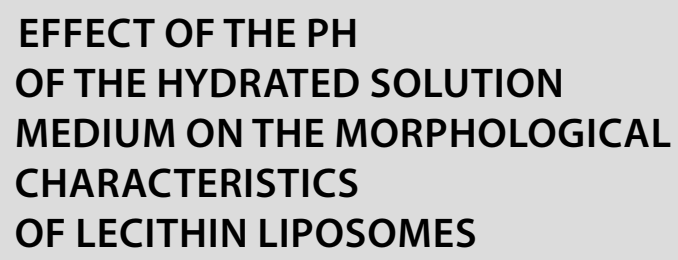

I. Shvetsov

Summary. The study is devoted to the study of the influence of the $\mathrm{pH}$ of the hydrated solution on the morphological characteristics of lecithin liposomes, namely: the stages of aggregation, the average size and distribution of the analyzed vesicles. For this purpose, solutions of sodium carbonate and magnesium chloride in concentrations of 5, 25,50 and 100 $\mathrm{mM}$ were used as hydrated solutions for the production of liposomes by phase reversal. The concentration of lecithin in the analyzed dispersion medium was $50 \mathrm{mg} / \mathrm{ml}$. The obtained lecithin liposomes were visualized by optical microscopy with a calibrated micrometer grid. As a result of the study, the optimal pH range of the hydrated solution was established 5.87-6.93, which should be achieved when encapsulating hydrophilic drugs in lecithin liposomes.

Keywords: liposomes, vesicles, lecithin, hydrated solution, hydrogen index, liposome morphology.

\section{Ввемение}

C пособности регулирования фармакокинетических параметров (всасывание, распределение, биотрансформация и выведение) лекарственных средств (ЛС), обеспечение нацеленного действия на органы и мишени и минимизация нежелательных реакций и побочных эффектов ЛС [11] - являются приоритетными направлениями персонализированной медицины и фармации. Один из способов реализации вышеуказанных направлений достигается разработкой транспортных терапевтических систем (ТTC) для направленной доставки ЛС [9], представленные лекарственными формами с пролонгированным действием, в которых ЛС диспергировано в матрице биополимера или инкапсулировано в защитную оболочку.

Самая популярная и широко применяемая на сегодняшний день ТТС является система доставки с использованием липосом (ЛПС) [10]. Данный факт подтверждается

\author{
Швецов Иван Сергеевич \\ Аспирант, Волгоградский государственный \\ медицинский университет, г. Волгоград \\ i.shvec95@mail.ru
}

Аннотация. Исследование посвящено изучению влияния рН среды гидратируемого раствора на морфологические характеристики лецитиновых липосом, а именно: стадии агрегации, средний размер и характер распределения анализируемых везикул. Для этого использовались растворы натрия карбоната и магния хлорида в концентрациях 5, 25, 50 и 100 мМ в качестве гидратируемых растворов для получения липосом методом обращения фаз. Концентрация лецитина в анализируемой дисперсионной среде составляла 50 мг/мл. Полученные лецитиновые липосомы визуализировались методом оптической микроскопии с откалиброванной микрометрической сеткой. В результате исследования установлен оптимальный диапазон рН гидратируемого раствора - 5,87-6,93, который должен быть достигнут при инкапсуляции гидрофильных лекарственных средств в лецитиновые липосомы.

Ключевые слова: липосомы, везикулы, лецитин, гидратируемый раствор, водородный показатель, морфология липосом.

использованием ЛПС в качестве ТТС для лечения онкологических $\left(\right.$ Doxil $^{\circledR}$, Depocyt ${ }^{\circledR}$ ) и грибковых заболеваний (Ambisome ${ }^{\circledR}$, Amphotec ${ }^{\circledR}$ ). Также разработаны анальгетические липосомальные препараты: DepoDur ${ }^{\circledR}$ - липосомальный морфина сульфат, Exparel ${ }^{\circledR}$ - липосомальный бупивакаин [4, 7].

ЛПС представляют собой везикулы, состоящие из фосфолипидного бислоя, который образует внутренний изолированный водный объем. Фосфолипидная природа ЛПС определяет их нетоксичность, биосовместимость и биоразлагаемость, а также способность инкапсулировать ЛС в зависимости от физико-химических свойств [5]. Так, гидрофильные ЛС инкапсулируются во внутренний объем, а липофильные ЛС заключаются в фосфолипидный бислой ЛПС [10]. В зависимости от применяемых технологий, методов и условий, могут быть получены ЛПС размерами от 10-1000 нм и более. При этом химические свойства используемых фосфолипидов определяют положительный или отрицательный 


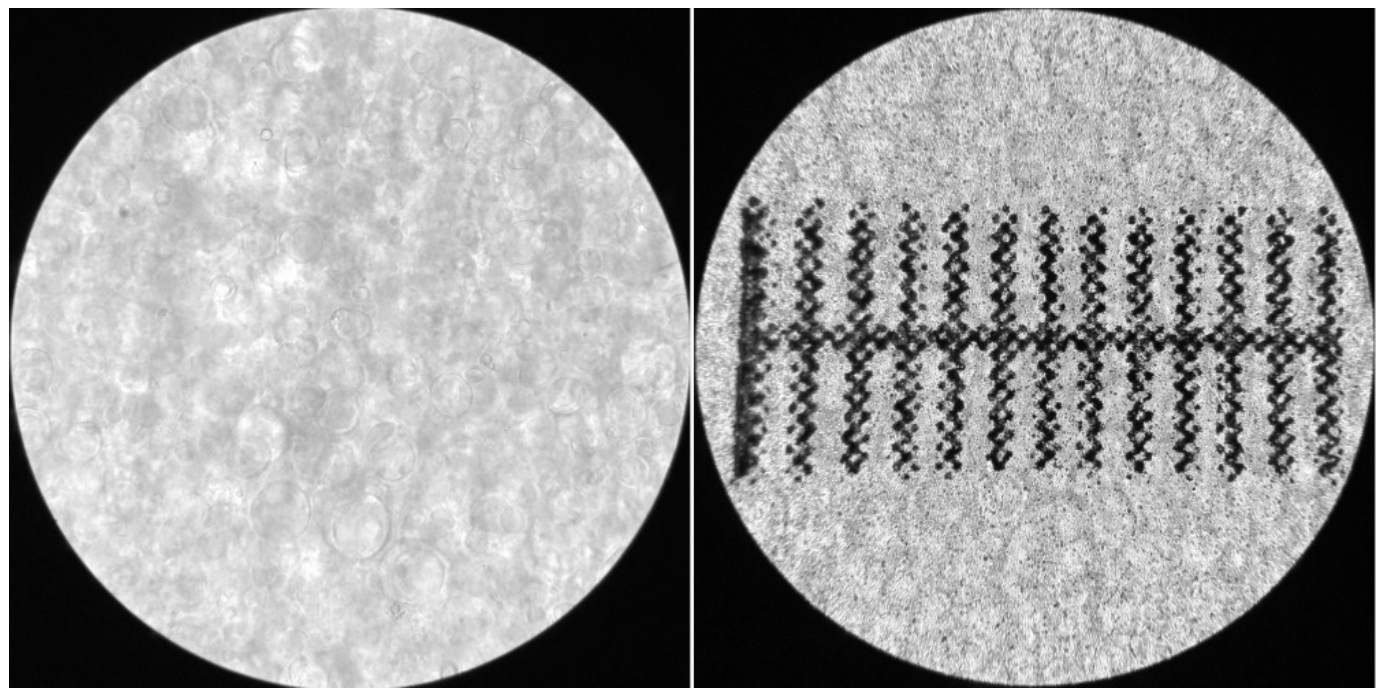

Рис. 1. Визуализация лецитиновых ЛПС, дисперсионная среда - вода очищенная

заряд на поверхности мембраны [4]. Применяемые методы функциональной модификации повышения эффективности применения ЛПС позволили получить длительно циркулирующие ЛПС, специфически нацеленные ЛПС, рН-чувствительные и светоинициируемые ЛПС [3].

Традиционным методом получения ЛПС является метод обращения фаз (метод гидратации липидной пленки), который включает следующие стадии: растворение фосфолипидов в органическом растворителе, выпаривание растворителя и получение липидной пленки, гидратация пленки с образованием гетерогенных ЛПС, и последующая гомогенизация с помощью экструзии или ультразвука до требуемых значений. В таком случае процесс образования ЛПС обусловлен энтропийно-обоснованной самосборкой фосфолипидов в везикулярные структуры в результате гидратации дисперсионной средой $[6,8]$.

Актуальность применения ЛПС в ТТС подтверждена современными исследованиями, которые направлены на разработку оптимальных фосфолипидных составов, условий и методов получения, способов достижения адресной доставки, а также изучение стабильности ЛПС $[3,4,5]$. Особое внимание исследователей направлено на изучение условий агрегации ЛПС, при которых ЛПС изменяют свою форму и образуют агрегаты с измененными физико-химическими характеристиками [2, 7].

Таким образом, цель данного исследования - определить влияние $\mathrm{pH}$ среды гидратируемого раствора на морфологические характеристики лецитиновых ЛПС.

Для достижения поставленной цели определены следующие задачи: 1) методом обращения фаз получить ле- цитиновые ЛПС с дисперсионными средами различной pH среды; 2) визуализировать полученные ЛПС методом оптической микроскопии и определить морфологические характеристики.

\section{Материалы и методы исслеАования}

Объектом исследования являлись ЛПС в разных дисперсионных средах, полученные методом обращения фаз [8]. В качестве источника фосфолипидов использовался подсолнечный лецитин (ООО «Ювикс-фарм», Россия, ТУ 9197-002-57531875-2015), который растворялся в достаточном количестве хлороформа, химически чистом (ООО «Компонент-Реактив», Россия, ТУ СОМР 2-028-06). Липидная пленка получалась выпариванием органического растворителя на ротационном испарителе R-213b, «SENCO Technology Co., Ltd.» (Китай). В качестве гидратируемых растворов использовалась вода очищенная, водные растворы магния хлорида и натрия карбоната в концентрациях 5, 25, 50, 100 мМ. Гидратация проводилась ручным встряхиванием до полного растворения пленки в дисперсионной среде. Полученная смесь пропускалась через воронку фильтровальную (ГОСТ 25336-82) с размерами пор 100 мкм. Концентрация фосфолипидов составляла 50 мг/мл.

Среда рН гидратируемых растворов фиксировалась потенциометрическим методом на $\mathrm{pH}$-метре $\mathrm{pH}-150 \mathrm{MИ}$, ООО «Измерительная техника» (Россия).

Везикулы визуализировались методом оптической микроскопии [1] с помощью светового микроскопа Биолам 70, «Bresser Optics» (Германия), с откалиброванной микрометрической сеткой, цена деления которой составляла 19 мкм при изучаемом увеличении в 40. 
Таблица 1. Характеристика гидратуемых растворов натрия карбоната и морфологические данные полученных везикул

\begin{tabular}{|l|l|l|l|l|}
\hline $\begin{array}{l}\text { Концентрация } \\
\text { гидратируемого } \\
\text { раствора натрия } \\
\text { карбоната, мМ }\end{array}$ & $\begin{array}{l}\text { рН среды } \\
\text { гидратируемого } \\
\text { раствора }\end{array}$ & $\begin{array}{l}\text { Стадия агрегации } \\
\text { везикул }\end{array}$ & $\begin{array}{l}\text { Средний размер } \\
\text { везикул / агрегатов, } \\
\text { мкм }\end{array}$ & $\begin{array}{l}\text { Процент наблюдаемых } \\
\text { везикул / агрегатов, } \\
\text { от исследуемой } \\
\text { области окуляра,\% }\end{array}$ \\
\hline 5 & 6,93 & Отсутствует & $26 \pm 1,2$ & $76 \pm 2,5$ \\
\hline 25 & 7,54 & Слабовыраженная & $35 \pm 1,5$ & $59 \pm 2,7$ \\
\hline 50 & 8,75 & Сильно выраженная & $47 \pm 2,1$ & $48 \pm 2,2$ \\
\hline 100 & 9,68 & Сильно выраженная & $56 \pm 2,6$ & $45+1,9$ \\
\hline
\end{tabular}

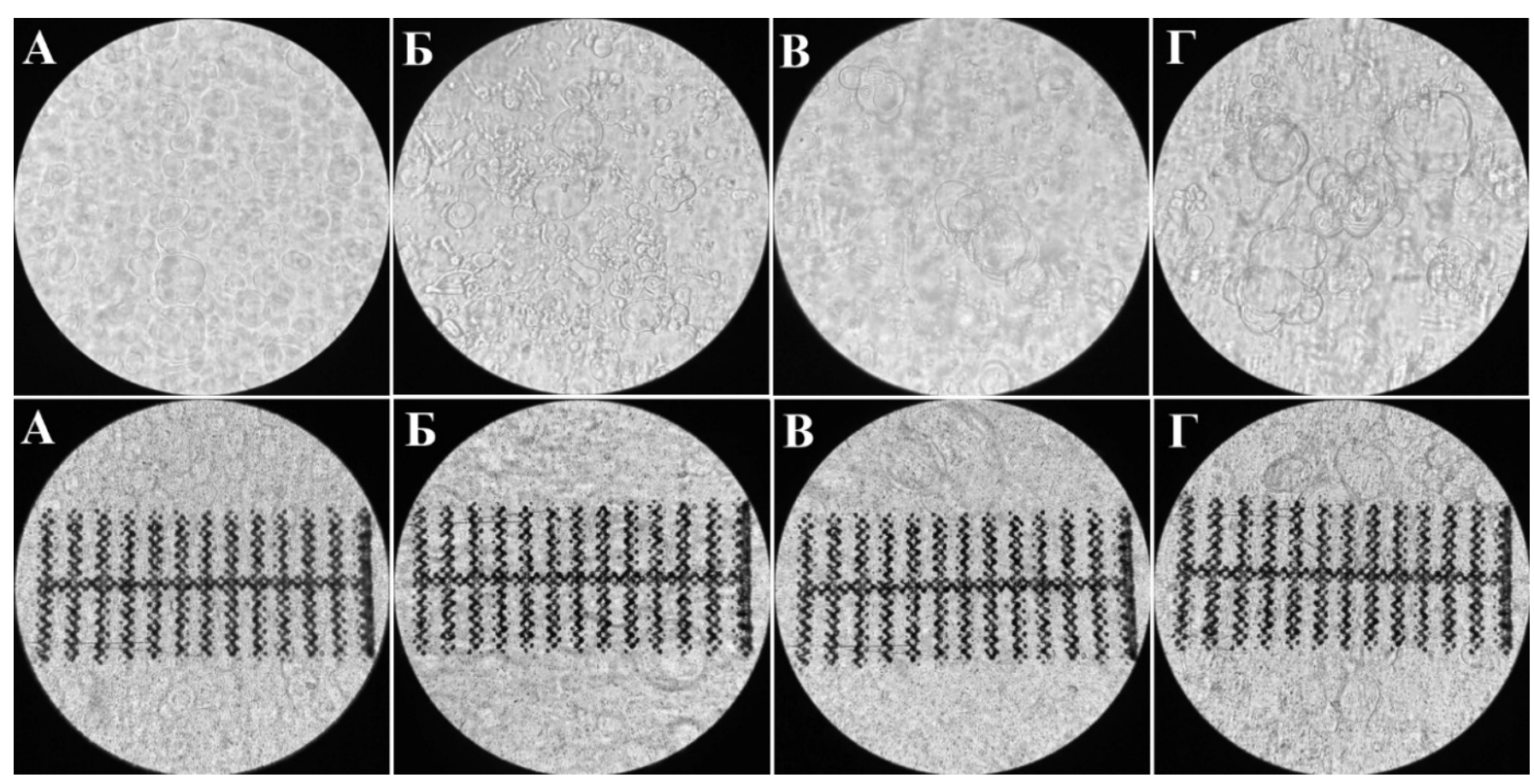

Рис. 2. Визуализация лецитиновых ЛПС, дисперсионная среда - раствор натрия карбоната в концентрациях: A 5 мМ, Б - 25 мМ, B - 50 мM, Г - 100 мM

\section{Результаты исследования}

На первом этапе исследования были получены ЛПС, где в качестве гидратируемого раствора использовалась вода очищенная, $\mathrm{pH}$ 6,54. Визуализация водного раствора ЛПС (рис. 1) показала следующие морфологические характеристики: отсутствие агрегации, сферическая форма везикул, средний размер - $25 \pm 1,1$ мкм, равномерное распределение в исследуемой области окуляра, процент наблюдаемых везикул от исследуемой области окуляра $-80 \pm 3 \%$.

На втором этапе, растворы натрия карбоната в концентрациях 5, 25, 50 и 100 мМ использовались в качестве дисперсионной среды для получения ЛПС. В результате визуализации ЛПС подтверждено наличие агрегации различного характера с образованием агрегатов (рис. 2), имеющие различные морфологические показатели (табл. 1).

Повышение концентрации свободных гидроксид-ионов $\left(\mathrm{OH}^{-}\right)$в гидратируемом растворе повлияло на морфологические характеристики готовых ЛПС. Так, при смещении рН среды в слабощелочную сторону - 7,54, наблюдалась слабовыраженная стадия агрегации ЛПС, которая характеризовались изменением формы везикул и концентрированием их отдельными группами. Дальнейшее повышение $\mathrm{pH}$ среды дисперсионной среды до 8,75 и 9,68, приводило к сильно выраженной агрегации ЛПС, проявляющейся слипанием и объединением везикул в крупные агрегаты. Таким образом, при увеличении $\mathrm{pH}$ среды гидратируемого раствора наблюдались 
Таблица 2. Характеристика гидратуемых растворов магния хлорида и морфологические данные полученных везикул

\begin{tabular}{|l|l|l|l|l|}
$\begin{array}{l}\text { Концентрация } \\
\text { гидратируемого } \\
\text { раствора магния } \\
\text { хлорида, мМ }\end{array}$ & $\begin{array}{l}\text { рН среды } \\
\text { гидратируемого } \\
\text { раствора }\end{array}$ & $\begin{array}{l}\text { Стадия агрегации } \\
\text { везикул }\end{array}$ & $\begin{array}{l}\text { Средний размер } \\
\text { везикул / агрегатов, } \\
\text { мкм }\end{array}$ & $\begin{array}{l}\text { Процент наблюдаемых } \\
\text { везикул / агрегатов } \\
\text { отследуемой } \\
\text { области окуляра,\% }\end{array}$ \\
\hline 5 & 5,87 & Отсутствует & $25 \pm 1,1$ & $79 \pm 3,8$ \\
\hline 25 & 5,11 & Начальная & $19 \pm 0,8$ & $54 \pm 2,6$ \\
\hline 50 & 4,49 & Слабовыраженная & $17 \pm 0,75$ & $41 \pm 1,9$ \\
\hline 100 & 3,97 & Слабовыраженная & $16 \pm 0,6$ & $33 \pm 1,5$ \\
\hline
\end{tabular}
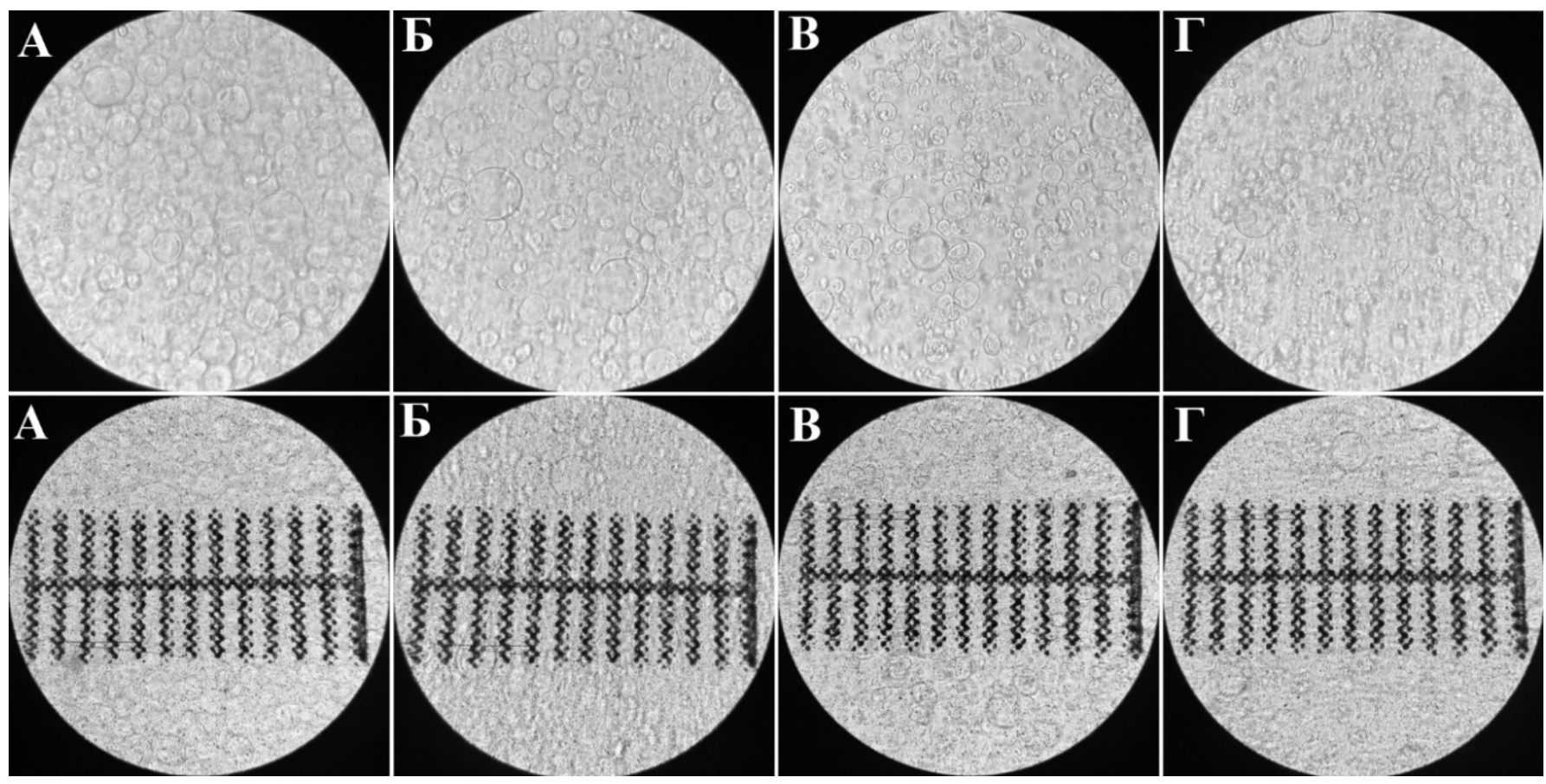

Рис. 3. Визуализация лецитиновых ЛПС, дисперсионная среда - раствор магния хлорида в концентрациях: A -5 мM, Б - 25 мM, B - 50 мM, Г - 100 мM

следующие тенденции: увеличение среднего размера везикул и их агрегатов с $26 \pm 1,2$ мкм до $56 \pm 2,6$ мкм, и уменьшение процента наблюдаемых везикул и их агрегатов с $76 \pm 2,5 \%$ до $45+1,9 \%$.

На заключительном этапе исследования были получены и проанализированы ЛПС с гидратируемыми растворами магния хлорида в концентрациях 5, 25, 50, 100 мМ. Визуализация ЛПС (рис. 3) подтвердила наличие начальной и слабовыраженной агрегации везикул при концентрации магния хлорида 50 и 100 мМ, однако морфологические данные имели расхождения при различных концентрациях солевого раствора (табл. 2).

Уменьшение $\mathrm{pH}$ дисперсионной среды, обусловленное увеличением свободных ионов водорода $\left(\mathrm{H}^{+}\right)$, также оказало влияние на морфологические характеристики ЛПС. Начальная и слабовыраженная стадия агрегации наблюдалась при рН 5,11, 4,49 и 3,97. Однако, с увеличением концентрации магния хлорида, наблюдаемый процент от исследуемой области окуляра и средний размер везикул и их агрегатов уменьшался от $25 \pm 1,1$ мкм и 79 \pm 3,8\%, до $16 \pm 0,6$ и $33 \pm 1,5 \%$ соответственно.

\section{Выво $\triangle \mathrm{b}$}

В результате проведенного исследования определено влияние $\mathrm{pH}$ среды гидратируемого раствора, на примере водных солевых растворов, на следующие морфологические характеристики лецитиновых ЛПС - стадия агрегации, средний размер и наблюдаемый процент в исследуемой области везикул и их агрегатов. 
Оптимальные значения $\mathrm{pH}$ дисперсионной среды находится в промежутке от 5,87 до 6,93. При этом, морфологические характеристики полученных ЛПС соответствуют характеристикам везикул в среде воды очищенной.

При изменении среды рН в более щелочную или кислую, наблюдается агрегация везикул с изменением их среднего размера и нарушается их распределение в дисперсионной среде. Данные факторы могут негатив- но оказывать влияние на качество и стабильность полученных ЛПС, в том числе, быть причиной низкой эффективности инкапсуляции ЛС в ЛПС.

Таким образом, при получении ЛПС методом обращения фаз, оптимальным условием является значение $\mathrm{pH}$ гидратируемого раствора от 5,87 до 6,93. Отсюда возникает необходимость в стабилизации рН водных растворов ЛС, которые не входят в данный диапазон, для возможности их инкапсуляции в лецитиновые ЛПС.

\section{ЛИТЕРАТУРА}

1. Advantages and limitations of current imaging techniques for characterizing liposome morphology / A.L. Robson, P.C. Dastoor, J. Flynn [et al.] // Front Pharmacol.2018. — Vol. 9. D0I: 10.3389/fphar.2018.00080

2. Aggregation of polyethylene glycol polymers suppresses receptor-mediated endocytosis of PEGylated liposomes / Z. Shen, H. Ye, M. Kröger, Y. Li // Nanoscale. 2018. — № 10 (9).—P. 4545-4560. D0I: 10.1039/c7nr09011k

3. Composition design and medical application of liposomes / M. Li, C. Du, N. Guo [et al.] // Eur J Med Chem. — 2019.— № 164.— P. 640-653. D0I: 10.1016/j. ejmech.2019.01.007

4. Drug nanocrystallisation within liposomes / T. Li, D. Cipolla, T. Rades, B.J. Boyd // J Control Release.— 2018.— № 288. — P. 96-110. D0I: 10.1016/j. jconrel.2018.09.001

5. Liposomes for drug delivery in stroke / G.E. Bruch, L.F. Fernandes, B.L.T. Bassi [et al.] // Brain Res Bull._ 2019.— № 152.— P. $246-256$.

6. Rideau E. Self-assembly of giant unilamellar vesicles by film hydration methodologies / E. Rideau, F.R. Wurm, K. Landfester // Adv Biosyst.— 2019. — № 3 (6). — D0I: 10.1002/adbi.201800324

7. Study on the in situ aggregation of liposomes with negatively charged phospholipids for use as injectable depot formulation / L. Rahnfeld, J. Thamm, F. Steiniger [et al.] // Colloids Surf B Biointerfaces.— 2018.— № 168.—P. 10-17. D0l: 10.1016/j.colsurfb.2018.02.023

8. Zhang H. Thin-film hydration followed by extrusion method for liposome preparation / H. Zhang // Methods Mol Biol.— 2017.— № 1522. — P. 17-22. D0I: 10.1007/978-1-4939-6591-5_2

9. Наноразмерные лекарственные средства: особенности оценки безопасности / Е.М. Бовина, Б.К. Романов, А.С. Казаков [и др.] // Безопасность и риск фармакотерапии. - 2019. - Т. 7, № 3.- С. 127-138.

10. Попова Е.А. Современные тенденции в разработке и производстве наноразмерных систем для доставки лекарственных соединений / Е.А. Попова, П.П. Бельтюков, А.С. Радилов // Научно-технический вестник информационных технологий, механики и оптики.— 2020.— Т. 2, № 2. - С. $206-222$.

11. Разработка липосомальных форм лекарственных препаратов: методы оценки и показатели качества / Е.В. Мельникова, Д.В. Горячев, А.А. Чапленко [и др.] // Вестник Российского государственного медицинского университета.— 2018. — № 6. — C. 35-42. 